\title{
Coesão discursiva nos Estudos de execução transcendental de Liszt: as últimas sete peças
}

\author{
Daniel Bento (UNESP, São Paulo, SP) \\ dbento@ig.com.br
}

\begin{abstract}
Resumo: Parece urgente a investigação dos processos de coesão nos Estudos de execução transcendental de Franz Liszt: a emergência de um todo unificado é sugerida já no plano tonal que os coordena. 0 exame de outros aspectos que pudessem garantir unidade - vinculados aos materiais específicos das composições - constitui o foco do presente trabalho. Seu recorte é o subconjunto formado pelas últimas sete peças do grupo, justificado pelo fato de elas demonstrarem uma afinidade particular, o salto de sexta ascendente antecedido por diferentes formas de ênfase. 0 fundamento teórico adotado é uma adaptação do conceito de subtematismo de Dahlhaus, que nutre o procedimento metodológico: a abordagem analítica. Os resultados mostram conexões baseadas não apenas em fenômenos harmônicos, mas também na recorrência de materiais flexiveis que sofrem transformações. Com isso, confirma-se a coesão dos recortes e a pertinência dos processos de integração no volume de Liszt.
\end{abstract}

Palavras-chave: análise musical; coesão musical; subtematismo; Franz Liszt.

\section{Discourse cohesion in Liszt's Transcendental studies: the last seven pieces}

Abstract: It seems to be urgent the investigation upon the cohesive processes in the Transcendental studies by Franz Liszt: the emergence of a unified whole is already suggested in the tonal plan that coordinates them. The examination of other aspects that could guarantee unity - related to specific materials of the compositions - is this text's main concern. Its focus is the subset formed by the last seven pieces of the group, and that is justified by the fact that they show a particular affiliation, the ascending leap of sixth preceded by different forms of emphasis. The theoretical basis adopted is an adaptation of Dahlhaus' concept of subthematicism, which supports the methodological procedure: the analytical approach. The results show connections based not only on harmonic phenomena, but also on the recurrence of flexible materials that are object of transformations. Hence, it is possible to substantiate the cohesion of the selected pieces and the relevance of the integration processes in Liszt's volume.

Keywords: musical analysis; musical cohesion; subthematicism; Franz Liszt.

\section{1 - Introdução}

Franz Liszt (1811-1886) termina seus Estudos de execução transcendental (Études d'exécution transcendante, $\mathrm{S}$ 139)' em 2 de abril de 1851; mas o processo envolvendo esse grupo formado por doze composições (publicadas em 1852) é muito anterior a tal data, concernindo mesmo aos seus primeiros anos de atividade composicional. Afinal, em 1826 criaria um conjunto que constituiria a origem da obra em questão, Estudo para o piano em quarenta e oito exercícios em todos os tons maiores e menores Op. $6^{2}$ (Étude pour le piano en quarante-huit exercices dans tous les tons majeurs et mineurs, S 136, com primeira publicação em 1827). Não bastasse isso, em 1837 terminaria uma outra versão do material, Vinte e quatro grandes Estudos ${ }^{3}$ (Vingtquatre grandes Études, S 137, livro publicado em 1839); e em 1840 faria uma revisão independente da peça em ré menor (S 138, publicada em 1847) que integra esse longo projeto (SAMSON, 2003, p.136-137, passim).
É relevante o fato de Liszt não ter abandonado - a despeito das consideráveis alterações ${ }^{4}$ que, ao longo de décadas, tenham sofrido os materiais relacionados aos Estudos de execução transcendental - um plano tonal específico que encadeasse essas peças. Tal plano definir-se-ia pelo movimento de terças entre as fundamentais das tonalidades. Numa observação mais detalhada, proporia a alternância entre tons maiores e menores marcada por deslocamentos descendentes de terça menor após os tons maiores e de terça maior após os menores. 0 resultado seria, de um ponto de vista funcional, a vizinhança entre tonalidades tanto relativas quanto anti-relativas. Desse modo, o primeiro Estudo far-se-ia em Dó maior; o segundo, em Lá menor; o terceiro, em Fá maior; o quarto, em Ré menor; e tal plano continuaria até a última composição, em Si bemol menor. 
Ou seja, não há dúvidas que Liszt tenha associado harmonicamente as doze composições dos Estudos de execução transcendental na versão final que recebe esse título e nas formulações anteriores. Não obstante, restaria investigar se conexões de outra ordem, vinculadas propriamente aos materiais utilizados, também patenteariam um processo coesivo, processo capaz de estabelecer uma dupla função discursiva: as partes integrantes do volume seriam independentes num primeiro patamar de fruição (as peças jamais perderiam suas autonomias formais, aspecto corretamente celebrado nos programas de recital, que com freqüência as separam); mas se poderiam associar em um nivel estrutural mais amplo tangendo tanto a pares ou subgrupos ainda maiores de peças quanto ao todo do livro. Essa investigação teria especial pertinência no caso da versã $0^{5}$ de 1851 , que se dá num período em que Liszt volta-se com particular interesse à composição e, em termos ainda mais específicos, a estratégias de coesão criativa. Dois anos depois, para se dar um exemplo bastante efetivo - atestado (dentre tantos outros) por SAMSON (2003, p.216), HAMILTON (1996, p.32, 44, passim), WALKER (2004, v.II, p.149-157) e ROSEN (1995, p.479-491) -, terminaria sua Sonata em Si menor (S 178, publicada em 1854), caso relevante de unidade num extenso discurso, em razão de contínuas afinidades de material, por sua vez garantidas pela transformação temática. ${ }^{6}$

Dado que dez dos doze Estudos de 1851 recebem títulos - Preludio ( $\left.n^{\circ} 1\right)$, Paysage $\left(n^{\circ} 3\right)$, Mazeppa $\left(n^{\circ} 4\right)$, Feux follets $\left(n^{\circ} 5\right)$, Vision $\left(n^{\circ} 6\right)$, Eroica $\left(n^{\circ} 7\right)$, Wilde Jagd ( $\left.n^{\circ} 8\right)$, Ricordanza ( $\left.n^{\circ} 9\right)$, Harmonies du soir $\left(n^{\circ} 11\right)$ e Chasse-neige ( $\left.n^{\circ} 12\right)$-, é incontornável indagar-se se a coesão das peças se poderia dar não mediante vínculos da arquitetura musical, mas por argumentos programáticos. A resposta mais rápida e efetiva para tal questionamento provém da versão de 1837, na qual nenhuma peça recebe qualquer título poético, a despeito de, mesmo assim, nela já se fazerem perceber (mais claramente do que na versão de 1826) as fundações materiais da revisão de 1851.

Liszt, como se pode ver, de fato associou essas suas composições a fatores extramusicais (lembrando-se que Preludio é exceção, já que o título é puramente funcional); e Mazeppa constitui, nesse sentido, o caso mais sólido, pois em seu fim há alusão textual à conclusão do poema homônimo de Victor Hugo ${ }^{7}$ (1802-1885). Mas tais manobras refletem, como afirma ROSEN (1995, p.499), pensamento posterior à composição, "estímulos à apreciação do ouvinte". Essa função dos títulos e mesmo de textos prefaciais na sua produção como um todo, inclusive no que tange a seus poemas sinfônicos, é reforçada pelo próprio Liszt - que afirma que "a única finalidade do programa é fazer uma alusão preliminar às motivações psicológicas que levaram o compositor a criar sua obra, motivações que ele tenta exprimir através dela" (Apud in WATSON, 1994, p.225) - e por autores voltados à sua música, a exemplo de WALKER (2004, v.ll, p.305, 307). Destaca-se que, até nos casos de maior referencialidade extramusical, ${ }^{8}$ o programa lisztiano não serve "propriamente como um plano de estrutura musical" (WATSON, 1994, p.156); e, desse modo, a investigação dos processos de coesão baseada na sintaxe musical em si mesma - proposta do presente trabalho - é justificada independentemente dos títulos dos Estudos e de quaisquer vínculos que possam manter com elementos extramusicais. Para tal investigação, seria necessário que se comentasse o conceito de subtematismo, de Carl Dahlhaus (1928-1989).

\section{2 - 0 subtematismo}

Dahlhaus entende como fenômeno subtemático a presença de elementos criativos que afetem a fruição das construções musicais sem se manifestarem nelas de forma estruturalmente rígida, definitiva. Tais elementos correspondem a proposições em essência abstratas, no limite perto da subliminalidade, que num certo sentido se fazem perceber mais através de suas variáveis atualizações materiais do que através de sua essência geradora, que não se limita a uma única formulação concreta.

É fácil notar que o termo, referindo-se a "tematismo", evoca a associação dos parâmetros intervalar (horizontal) e rítmico, própria da idéia de "tema". Todavia, Dahlhaus assume como representantes do subtematismo ocorrências que não precisam patentear tal vínculo (DAHLHAUS, 1993, p.216-218). Alguns dos seus casos que nesse sentido devem ser considerados esclarecedores (BENTO, ZAMPRONHA, 2007, p.3-4) integrarão o presente tópico. Após isso, indicar-se-á os termos em que o subtematismo requer adaptação - e resultante expansão - para viabilizar o tipo de estudo aqui proposto.

A obra tardia e pré-tardia de Ludwig van Beethoven (1770-1827) representa o contexto original das formulações de Dahlhaus acerca do subtematismo. Nessa produção, o autor trata, dentre outras composições, do primeiro movimento da Sonata para piano em Mi bemol maior Op. 81a (1810), Les adieux. Destaca, nele, ocorrência subtemática isolada no parâmetro intervalar, ${ }^{9}$ baseada no cromatismo descendente - uma "sombra" (DAHLHAUS, 1993, p.209) acompanhando temas e outros componentes da superfície formal.

Como poderá ver o leitor, a seguinte reflexão sobre o primeiro movimento de Les adieux e a posterior ilustração (Ex.1) comprovam que, no subtematismo, a dimensão intervalar não precisa vincular-se à rítmica (que é variada demais nas manifestações cromáticas da composição), apesar de tal integração ser em certa medida esperada diante da própria alusão a "tematismo" 10 no termo criado por Dahlhaus:

É claro como resultado, de fato até mais do que claro, que, a despeito de nunca o cromatismo ser um tema, no sentido de aparecer numa Gestalt temática, ainda assim, como estrutura 'subtemática', ele tem tão formidável influência no processo formal quanto os temas que poderiam ser vistos de fora como fundação do desenvolvimento musical (Op. cit., p.209-210). 

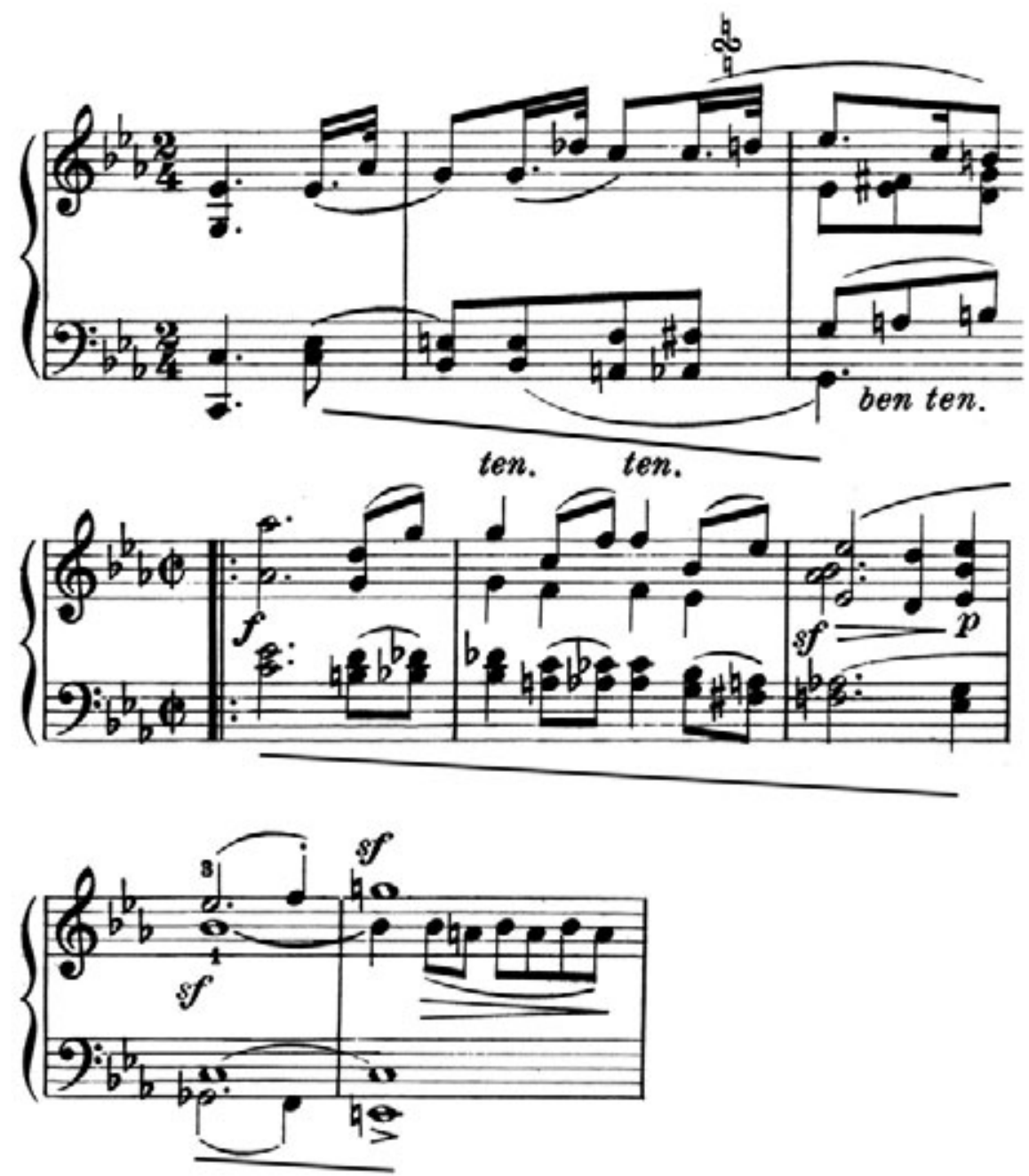

Ex.1 - Cromatismo subtemático na mão esquerda no Primeiro movimento da Sonata Les adieux de Beethoven (c.2-4, 17-19, 37-38).

Num outro caso de subtematismo, desta vez o parâmetro intervalar horizontal fica totalmente de fora; e é a ação harmônica que passa a ter força, dividindo importância com a rítmica (Op. cit., p.216-218).

Numa das últimas sonatas para piano beethovenianas, a Op. 110 (1822), em Lá bemol maior, o compositor estabelece conexões relevantes porém materialmente abertas. Vê-se isso no primeiro movimento, no começo da transição (c.12-15), que tem construção vertical diretamente ligada aos quatro compassos iniciais da obra, definidos por tônica, dominante com sétima ${ }^{11}$ em segunda inversão, tônica em primeira inversão e dominante com sétima. Mas esses segmentos divergem consideravelmente no geral - a tal ponto que a descrição verbal da harmonia (feita acima) é mais efetiva do que a ilustração musical (que mais patentearia as diferenças dos trechos).

Soma-se à ocorrência um processo paralelo, pois a primeira metade da progressão harmônica citada - tônica e dominante com sétima em segunda inversão - também ganha importância nos c.5-6. Com isso, considerando-se os c.1-2, c.5-6 e c.12-13, vê-se que se firma junto à harmonia uma aceleração rítmica: chega a haver semínima pontuada no 1, mas no 50 acompanhamento faz-se em semicolcheias, e finalmente no 12 aparecem as fusas.

Em suma, no primeiro movimento da 0p. 110 há um "'subtemático' curso de eventos" (Op. cit., p.216) que, em suas bases, prescinde do parâmetro intervalar horizontal.

Portanto, vê-se nesses casos que a relação do subtematismo com o tipo de entidade musical normalmente chamada de "tema" é bastante tênue, mesmo com a utilização do prefixo "sub-". Afinal, o subtematismo não só não necessariamente associa os parâmetros intervalar (horizontal) e rítmico como pode dispensá-los, nutrindo-se de outros dados musicais. Nesse sentido, sua relação com os processos temáticos justifica-se apenas no fato de haver tanto nesses últimos quanto no subtematismo alguma sorte de proposição que na composição demonstre pertinência. Contudo, no conceito de Dahlhaus, tal pertinência 
é mais conceitual do que puramente material, visto que o elemento subtemático não é uma entidade cristalizada; ele mais se materializa do que é, em si mesmo, material. Seus frutos manifestam-se na escrita; mas a diretriz que os gera continua a apontar para uma idéia, para um comportamento abstrato. Isso exposto, comenta-se a seguir os dois pormenores que fazem o subtematismo aqui sofrer adaptação e, em certa medida, expansão.

Em primeiro lugar, sendo empregado nos Estudos de execução transcendental de Liszt, o subtematismo emancipa-se da produção tardia e pré-tardia de Beethoven, seu âmbito original. Ainda que tal produção traia, em diversas situações, relações que indiquem um princípio abstrato que se materializa de modos variados na composição, o processo jamais poderia ser considerado exclusividade do mestre do classicismo. Basta que se pense, por exemplo, na suite de variação barroca ${ }^{12}$ e numa obra que bem a represente como a primeira Suite francesa (BWV 812, composta entre 1722 e 1725) de Johann Sebastian Bach (1685-1750), cujas partes, das mais variadas maneiras, nutrem-se da sucessão Ré-Lá-Si bemol-Lá (BENTO, 2006, p.375) - para que se constate que os recortes beethovenianos de DahIhaus podem, sim, ser especialmente interessantes no que diz respeito a seu conceito; mas de forma alguma estabelecem os limites repertoriais de suas implicações.

Em segundo lugar, Dahlhaus mais utiliza o subtematismo para identificar aspectos de coesão próprios de uma única composição: não desenvolve sua possibilidade de mediar a associação de diferentes peças. 0 autor chega, de fato, a esboçar isso quando mapeia um perfil abstrato definido por dois semitons separados por intervalos variáveis, per- fil comum aos quartetos de cordas em Lá menor 0p. 132 (1825), em Dó sustenido menor Op. 131 (1826) e em Si bemol maior opp. 130 (1826) e 133 (Grande fuga, 1826), ${ }^{13}$ de Beethoven (Id., 1989, p.83).

Paralelamente, aponta aproximações subtemáticas entre movimentos diferentes da já citada Sonata para piano Op. 110 (/d., 1993, p.217). Mas pensa no subtematismo primordialmente como ferramenta limitada às fronteiras da peça individual.

\section{3 - Os sete últimos Estudos de execução transcendental}

Existe um aspecto precipuo que une os Estudos de execução transcendental de números $6,7,8,9,10,11$ e 12 . Ainda que firme a abstração que caracteriza o subtematismo - seu processo de fazer-se perceber em contextos que apontem para uma idéia que mais materialize do que seja, em termos mais estritos, material em si mesmo - , tal aspecto recebe considerável ênfase ao longo dessas sete composições. É mais audível (e, na partitura, visivel) do que qualquer outro fenômeno do livro que se compatibilize com o pensamento de Dahlhaus (e essa afirmação é válida mesmo se se considerar as outras cinco peças que o integram). Como perfil conceitual que, das mais diversas formas, se cristaliza, pode ser definido pelo salto ascendente de sexta (maior ou menor), antecedido por alguma sorte de ênfase na primeira nota que o componha. É essa ênfase que faz com que um movimento tão elementar quanto esse salto ganhe surpreendente importância no volume, ainda que como uma "sombra" (para se lembrar de já citado termo empregado por Dahlhaus) de seus temas.

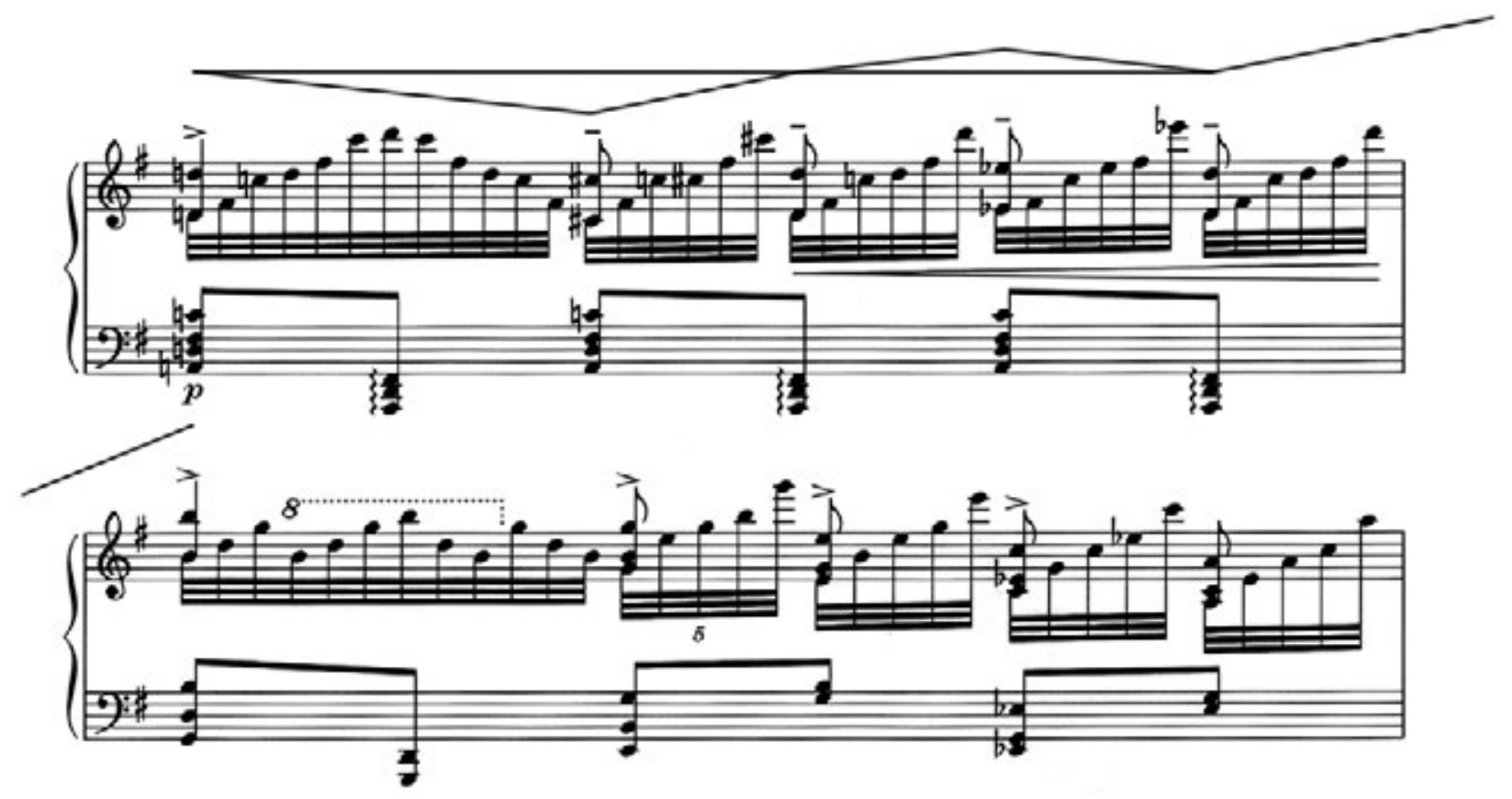

Ex.2 - Estudo $n^{\circ} 6$ de Liszt (c.44-45): Nota Ré cercada por Dó sustenido e Mi bemol, integrando em seguida salto de sexta ascendente. 


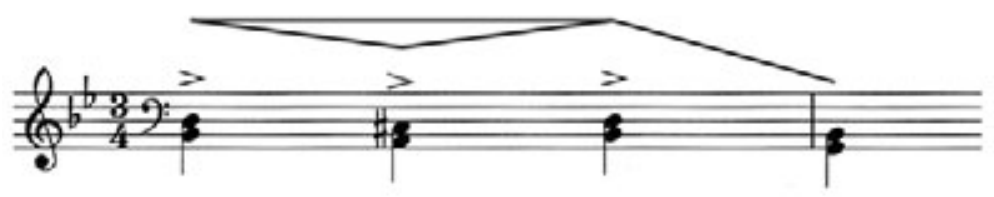

Ex.3 - Início do Estudo n 6 de Liszt (c.1-2).

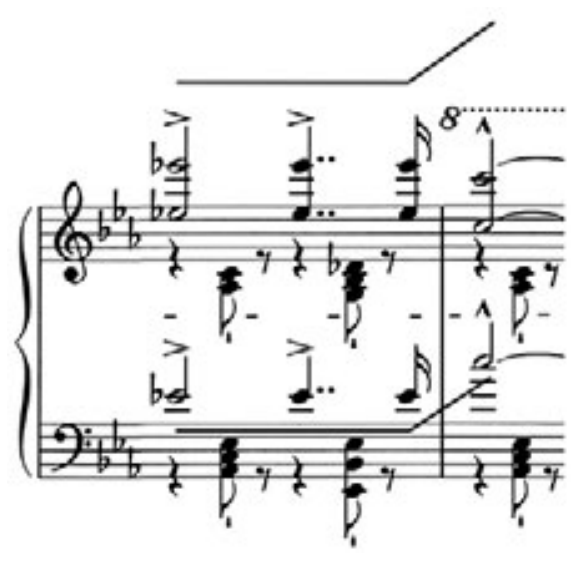

Ex.4 - Estudo no 7 de Liszt (c.38-39).

0 perfil mencionado não surge no começo da composição $n^{\circ} 6$ (Vision), em Sol menor, mas apenas a partir do c.44 - doze compassos, assim, antes da coda. Nesse ponto, a nota Ré ganha destaque por aparecer três vezes e por ser cercada cromaticamente por Dó sustenido e Mi bemol, que estabelecem bordaduras. Após, com a nota Si, no c.45, consuma-se o salto de sexta maior (Ex.2).

Liszt, logo, introduz na sexta peça elemento que marcará porção maior do que a metade dos Estudos de execução transcendental; só que o faz muito após ter estabelecido o tema e grande parte da estrutura dessa composição, num certo sentido mascarando, ao menos nesse momento inicial, o papel de tal elemento. Isso gera um interessante desdobramento: o c.44 tem importância maior no contexto global do volume musical lisztiano do que no contexto particular do sexto Estudo.

No entanto, mesmo se firmando tal interessante desdobramento, é necessário grifar-se que esse desenho do Estudo n 6 - que corresponde à materialização do subtemático movimento ascendente de sexta antecedido por ênfase na sua primeira nota - emerge pela transformação temática, tão importante na produção madura de Liszt (WATSON, 1994, p.201, 158). Evidencia-se isso ao se observar parte do tema da peça (Ex.3), com bordadura e salto descendente de terça (inversão, afinal, do deslocamento de sexta ascendente); salto esse que, por seu turno, obviamente se vincula ao plano tonal de terças descendentes do volume, inclusive por aparecer com reforços harmônicos que espelham esses intervalos. Em suma, a propriedade subtemática aqui em discussão se relaciona a uma idéia primordial do livro, isto é, sua fundação harmônica geral, presente já desde a versão de 1826 .

No Estudo $n^{\circ} 7$ (Eroica, em Mi bemol maior), como no seu predecessor, a partir de certo ponto se cristaliza o perfil conceitual do salto ascendente de sexta antecedido por alguma sorte de ênfase na primeira nota; e tal ponto é o c.38 (Ex.4, com a sexta maior), que integra a primeira variação do tema. Desta vez, a ênfase na primeira nota do salto consuma-se pela simples repetição: não há bordaduras. Comparando-se o que se vê na sétima peça, a essa altura, com a estrutura que emerge no anterior Estudo $n^{\circ}$ 6 (Ex.2, acima), pode-se finalmente perceber, em Liszt, característica tão importante no subtematismo a que chega Dahlhaus, impulsionado por Beethoven. Tal característica já se impõe como corolário das reflexões apresentadas na segunda seção deste texto. Porém, é agora demonstrada com facilidade: as amplas divergências entre os materiais, a despeito de serem eles frutos de um mesmo perfil conceitual, são precisamente o que garante o relevo da qualidade abstrata de seu princípio gerador.

Na composição em Dó menor, Estudo n 8 (Wilde Jagd), o elemento subtemático aqui demonstrado se manifesta claramente de três maneiras. A primeira assume a ênfase na primeira nota do salto (de sexta menor) pela subida e descida cromática, que em tal nota tanto se inicia quanto se encerra (Ex.5); a segunda patenteia um desenho muito próximo daquele encontrado na sétima peça (Ex.6, sexta maior), apesar das divergências rítmicas; e a terceira garante por repetição (ainda que com a interpolação de outras notas) o destaque à altura que principia o salto (Ex.7, sexta maior). 


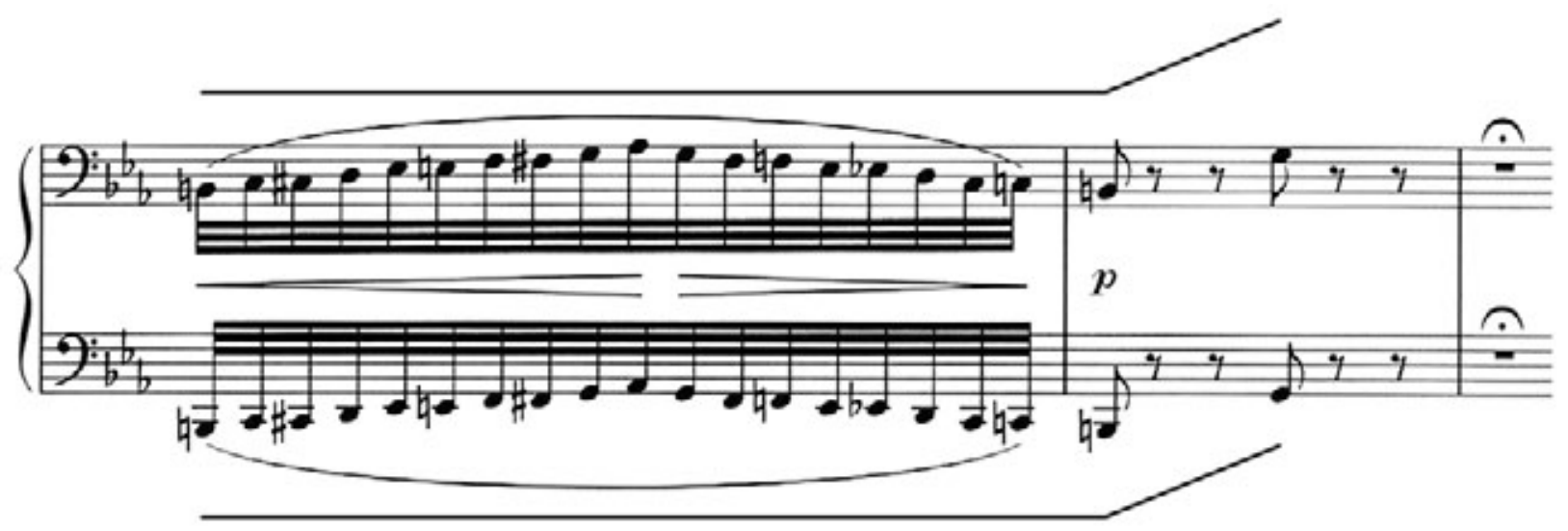

Ex.5 - Estudo nº 8 de Liszt, introdução (c.29-30).

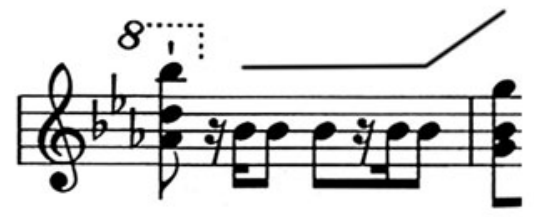

Ex.6 - Estudo nº 8 de Liszt, final da introdução (c.58-59).

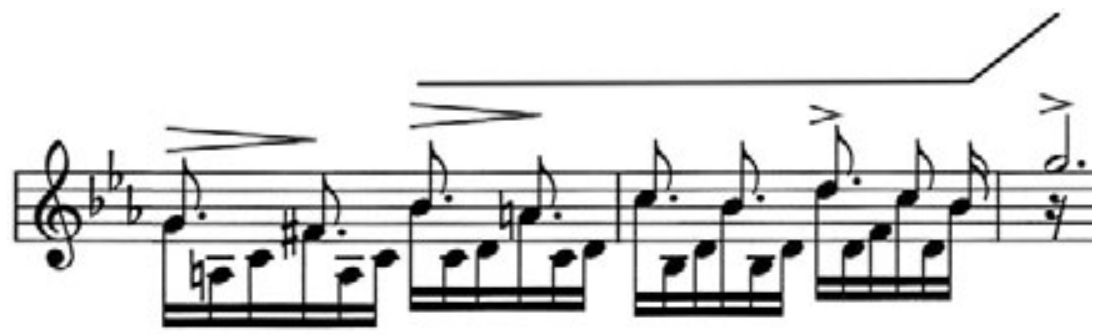

Ex.7 - Estudo no 8 de Liszt, segundo tema (c.91-93).

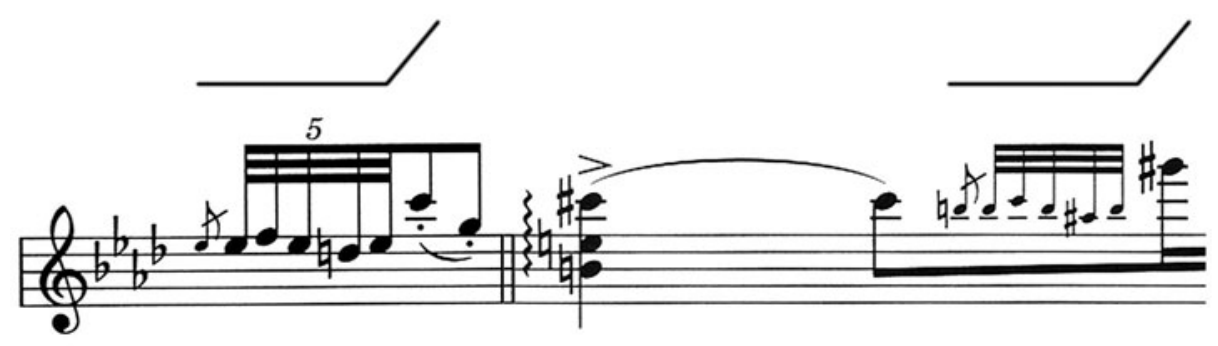

Ex.8 - Estudo no 9 de Liszt (c.14, 30).

Pode-se vislumbrar, a esta altura, o efeito acumulativo dessas estruturas no decurso dos Estudos de execução transcendental. É por meio desse pormenor que o princípio subtemático por trás delas se impõe como fator de grande significância. Nesse contexto, grifa-se que a percepção do processo aqui em destaque se vai favorecendo cada vez mais, conforme o conjunto de obras que se interligam avança em seu próprio discurso.
0 Estudo n 9 (Ricordanza), em Lá bemol maior, dá continuidade às associações. Ocorrências do salto de sexta maior ascendente com sua primeira nota enfatizada nele são numerosas, tendo importância no próprio contexto melódico da composição e fazendo-se próximas, entre si, nas suas linhas gerais: a primeira altura da sexta é basicamente objeto de ornamentação. Apresenta-se acima (Ex.8) a ocorrência fundamental do processo, no c.14, 
bem como outra manifestação, no 30. Contudo, muitos pontos da peça poderiam também servir de ilustração (como atestam os c.49-50 e c.97, dentre tantos outros).

Chegando-se ao décimo Estudo, em Fá menor, vê-se que seu primeiro tema tem um dos seus traços mais marcantes no salto ascendente de sexta (menor) antecedido por ênfase na primeira nota que o compõe (comprovam isso os c. 6, c.7-9, c.22-23, c.25-26, c.27-28, dentre outros). Nele, a nota que principia o salto é cercada cromaticamente (Ex.9).

No caso da peça no 11 (Harmonies du soir, em Ré bemol maior), o perfil subtemático estudado é comum. 0 início da composição já o patenteia, pelas repetições de Lá bemol (c.1) que antecedem a entrada da mão direita (c.2), esta com nota superior sexta menor (composta) acima das reiteradas alturas da outra mão. Logo depois, ainda, mais uma ocorrência se firma: a citada entrada destaca posteriormente Ré bemol, nota superior que é cercada por outras alturas e seguida, após, por Si dobrado bemol (estabelecendo-se dessa forma outro salto de sexta menor ascendente). Além desses exemplos (Ex.10), alguns outros poderiam ser dados (c.11-12, 58-59, 70-71).

Finalmente, verifica-se a destacada presença, no último Estudo (Chasse-neige), em Si bemol menor, do salto ascendente de sexta antecedido por ênfase na sua primeira nota. Em alguns casos, o processo é complexo: Liszt constrói o salto ascendente de sexta maior; mas, entre o ponto de partida - novamente enfatizado ao ser cercado cromaticamente - e o de chegada, insere uma apojatura, apojatura esta que por enarmonia também estabelece o salto de sexta, ainda que menor (Ex.11, com o salto Lá bemol-Fá e a apojatura Mi bequadro). 0 fenômeno repete-se em pontos como os c.11-12, c.57-58, c.59-60. Todavia, não bastasse isso, vê-se outros casos, em que o salto de sexta com primeira nota enfatizada dá-se sem apojatura intercalada (c.14-15 e c.52, por exemplo), de modo direto, portanto.

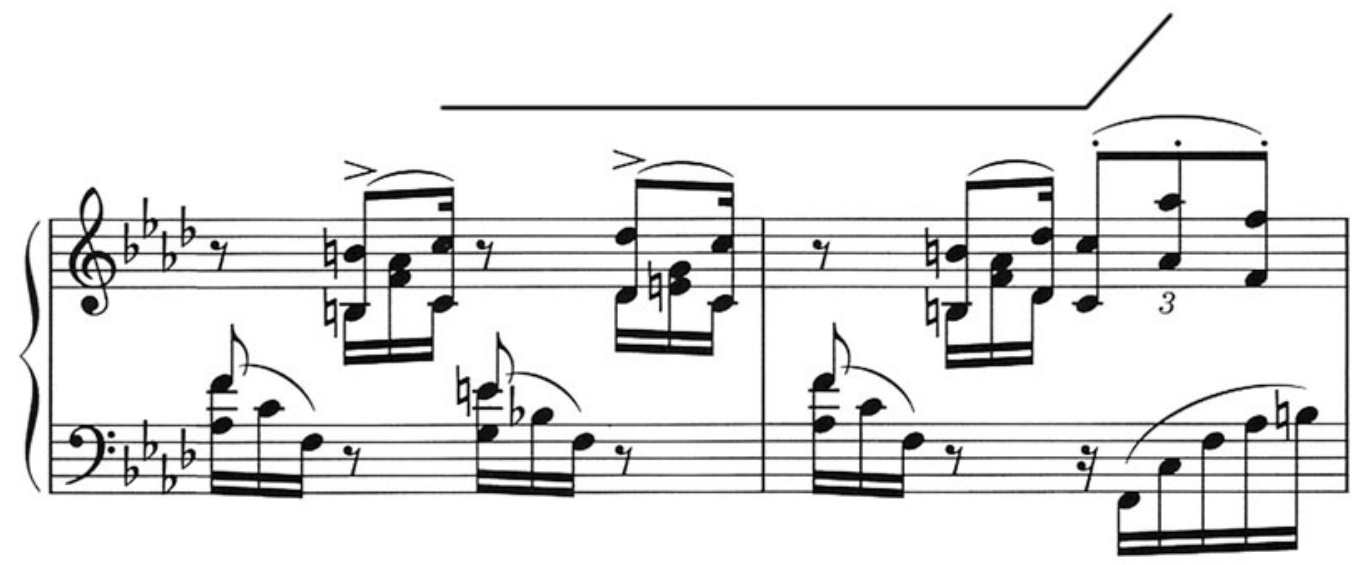

Ex.9 - Estudo no 10 de Liszt (c.6-7).

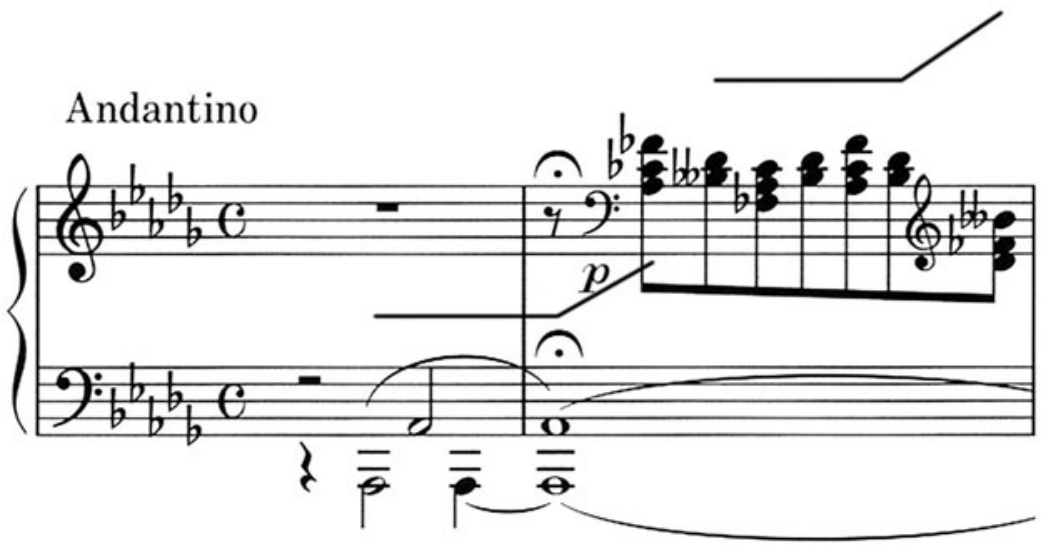

Ex.10 - Estudo no 11 de Liszt (c.1-2). 


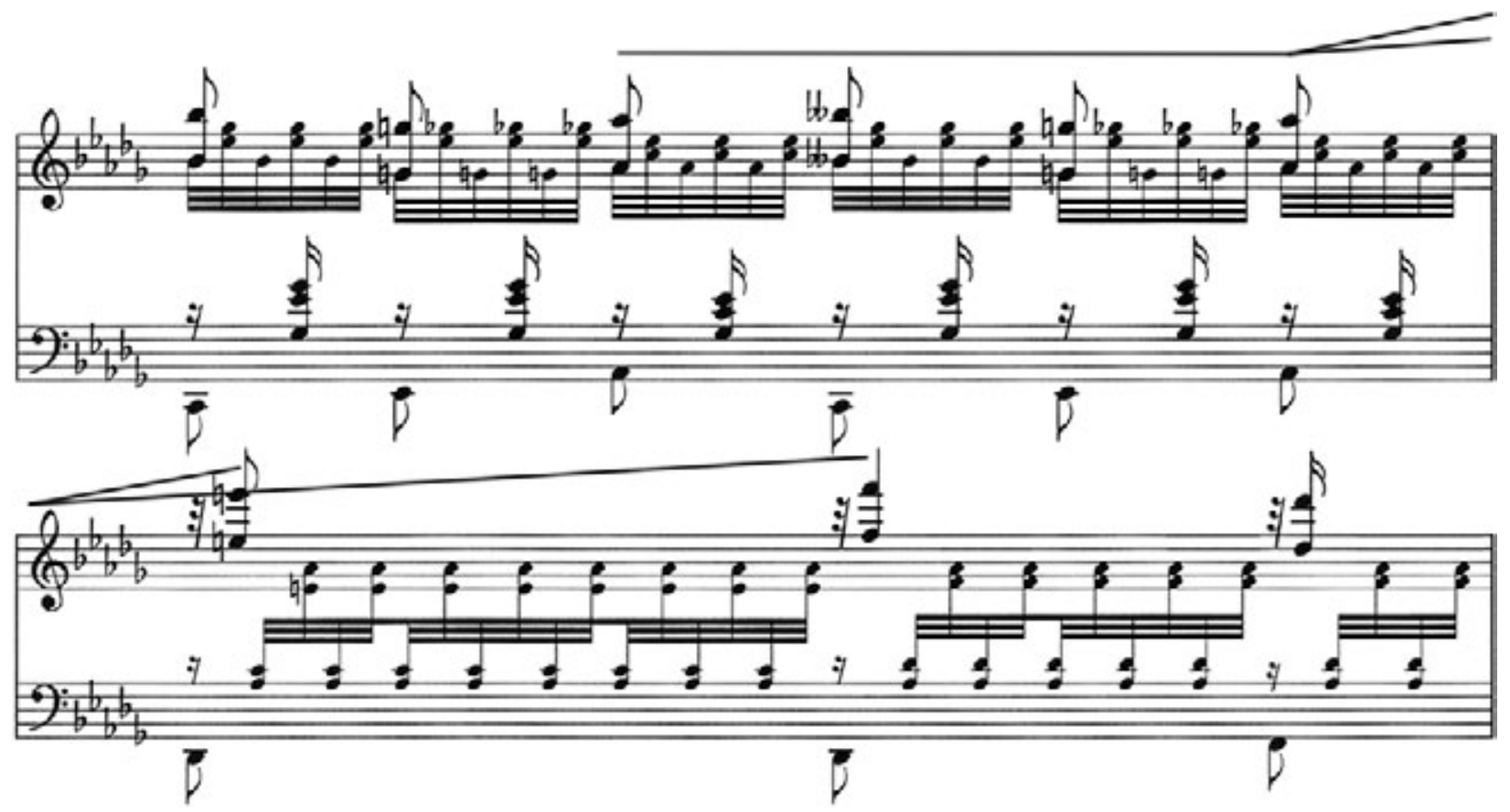

Ex.11 - Estudo no 12 de Liszt (c.9-10).

0 que se vê nesses sete Estudos, destarte, é um processo coesivo que vai muito além daquele sugerido pelo mero encadeamento tonal do volume, pois garante que os materiais das peças firmem conexões - tênues, afinal, porque jamais ocorre entre as composições situação óbvia como a reaparição (ou a reformulação) de um tema. Tais materiais acima discutidos traem transformações, se comparados entre si; grifam um princípio gerador comum, cujos resultados, plurais, apontam para a abstração. Esse princípio é de natureza subtemática.

\section{4 - Considerações finais}

Outros processos coesivos poderiam ser adicionados à grande união múltipla aqui estudada, formada pelas sete últimas composições dos Estudos de execução transcendental. Concernem a dois pares de peças e fundamentam-se basicamente em relações harmônicas.

No primeiro par, formado pelos Estudos $n^{0} 7$ e $n^{\circ} 8$, há algo além da aproximação por tonalidades relativas, pois os dois temas do $n^{0} 8$ (principiando o primeiro deles no c.59 e o segundo no c.85) constroem-se inicialmente na tonalidade do $n^{\circ} 7$, isto é, Mi bemol maior. Essa anomalia numa estrutura que no geral dialoga com a forma-sonata parece relacionar-se diretamente com a tendência de integração das composições do livro.
Por seu turno, no segundo par, que corresponde às composições $n^{\circ} 11$ e $n^{\circ} 12$, há planos tonais que se aproximam diante da retrogradação e da transposição. Afinal, podese sintetizar o percurso harmônico do Estudo $n^{\circ} 11$ por Ré bemol maior (início), Sol maior (a partir do c.38), Mi maior (58) e Ré bemol maior (98); e o caminho do $\mathrm{n}^{\circ} 12$ se estabelece através de Si bemol menor (início), Ré bemol maior/menor (9), Mi maior (25) e Si bemol menor (36). Vê-se ainda, nesse contexto, que há dois centros comuns às peças, Ré bemol e Mi.

Por fim, deve-se acrescentar que no volume de Liszt não há apenas coesão (justificada em materiais particulares) envolvendo as últimas sete peças. Outras relações de integração encontram espaço nas primeiras composições dos Estudos de execução transcendental (tratando exatamente delas o segundo trabalho que consta das Referências deste artigo). Assim, ainda que as últimas sete criações apresentem o mais notável fenômeno subtemático do livro - que lhes caracteriza e não ocorre nas peças anteriores -, os Estudos de execução transcendental estabelecem um processo maior, envolvendo suas doze partes. Os desdobramentos (inclusive formais) dessa grande associação em muito transcendem as dimensões destinadas ao presente texto. 


\section{Referências}

BENTO, Daniel. Bach em Chopin: comunicação, influência e permanência nos manuais do teclado. São Paulo, 2006. Tese (Doutorado em Comunicação e Semiótica) - Programa de Estudos Pós-Graduados em Comunicação e Semiótica, Pontifícia Universidade Católica de São Paulo.

BENTO, Daniel, ZAMPRONHA, Edson. Coesão discursiva nos Estudos de execução transcendental de Liszt: primeiras seis peças. In: CONGRESSO DA ASSOCIAÇÃO NACIONAL DE PESOUISA E PÓS-GRADUAÇÃO EM MÚSICA (ANPPOM), XVII, 2007, São Paulo. Anais... São Paulo: ANPPOM/IA-UNESP, 2007. p.1-9. CD-ROM.

DAHLHAUS, Carl. Ludwig van Beethoven: approaches to his music. Trad. Mary Whitall. Oxford: Oxford university press, 1993.

. Nineteenth-century music. Trad. J. Bradford Robinson. Berkeley, Los Angeles, London: University of California press, 1989.

HAMILTON, Kenneth. Liszt: Sonata in B minor. Cambridge: Cambridge university press, 1996.

ROSEN, Charles. The romantic generation. Cambridge: Harvard university press, 1995.

SAMSON, Jim. Virtuosity and the musical work: the Transcendental studies of Liszt. Cambridge: Cambridge university press, 2003.

WALKER, Alan. Franz Liszt. Ithaca: Cornell university press, 2004. 3v.

WATSON, Derek. Liszt. Trad. Clóvis Marques. Rio de Janeiro: Jorge Zahar editor, 1994. (Estante de música).

\section{Notas}

1 Catálogo de obras de Liszt organizado por Humphrey Searle (1915-1982).

2 'O título faz referência a quarenta e oito peças, dando a entender que as doze então publicadas seriam apenas o primeiro de quatro volumes. Todavia, os outros três volumes jamais foram elaborados.

3 Ocorre aqui, como se pode ver, questão similar à do volume de 1826: Liszt assume um número de peças (vinte e quatro em 1837) que não corresponde ao efetivamente encontrado na publicação. Assim, mais uma vez se supõe que tenha planejado uma continuação (através de volume posterior), nunca consumada.

4 A maior alteração sem dúvida diz respeito à total exclusão, em versões posteriores, dos materiais da composição no 11 de 1826. Em função dessa eliminação, Liszt transpõe para Ré bemol maior as idéias da peça $\mathrm{n}^{\circ} 7$ desse ano (originalmente em Mi bemol maior), a partir disso chegando a um outro Estudo no $11 \mathrm{em} \mathrm{1837,} \mathrm{que} \mathrm{nutrirá} \mathrm{a} \mathrm{composição} \mathrm{correspondente} \mathrm{de} \mathrm{1851.} \mathrm{Paralela-}$ mente, elabora novo material para ocupar o lugar da transposta composição n 7 , como comprova o volume da década de 1830 - que também nesse caso serve de base para o da década de 1850.

5 Vinculada a pesquisa de Pós-Doutorado atualmente desenvolvida pelo autor no Instituto de Artes da UNESP, com bolsa da FAPESP. Em seu primeiro estágio, a pesquisa é supervisionada pelo compositor Edson Zampronha; após, passa a ser pelo atual diretor do Instituto, Marcos Pupo Nogueira.

6 A transformação temática pode ser definida como uma técnica baseada tanto na variação quanto no desenvolvimento de estruturas temáticas. Por meio dela, temas diferentes ou contrastantes se revelam, após observação mais atenta, manifestações de um mesmo componente criativo.

7 Parte de As orientais (Les orientales), obra de Hugo publicada em 1829.

8 Como a segunda das Duas lendas (S 175, 1863): Lenda de São Francisco de Paula marchando sobre as ondas.

9 Dahlhaus menciona a "quarta" cromática descendente como elemento integrador (1993, p. 209); mas a estruturação exclusiva desse intervalo não é imprescindível na obra.

10 Afinal, "tema" pressupõe a cristalização de uma proposição intervalar-rítmica - nem apenas intervalar nem apenas rítmica.

11 Todavia, nessa última harmonia há alguma divergência não mencionada por Dahlhaus (1993, p. 216), se se comparar o c.15 como c.4. Neste, vê-se dominante com sétima em estado fundamental; naquele, dominante com sétima em primeira inversão.

12 A suíte de variação caracteriza-se por relações unificadoras entre suas diferentes peças, relações que podem concernir a materiais motívicos ou a planos tonais aparentados.

13 Originalmente parte do Op.130.

Daniel Bento é Professor pesquisador do Instituto de Artes da Universidade Estadual Paulista, com bolsa de Pós-Doutorado da FAPESP. Seus trabalhos publicados nos últimos anos vêm envolvendo interligações entre a análise musical, a estética e a performance. Bacharel em Composição e Regência pelo citado Instituto, é também Mestre (bolsa CNPq) e Doutor (bolsa FAPESP) em Comunicação e Semiótica pela Pontifícia Universidade Católica de São Paulo. Na graduação, sua pesquisa de Iniciação Científica (bolsa FAPESP) foi premiada no XI Congresso de Iniciação Científica da UNESP (1999) e tornou-se o livro Beethoven, o princípio da modernidade (Annablume/FAPESP, 2002). Seu próximo livro - A Nona sinfonia e seu duplo - será publicado em breve pela Editora da UNESP. 